\title{
Sesli Kitaplarm Yabancı Dil Olarak Türkçe Öğrenenlerin Okumaya Yönelik Tutumları Üzerindeki Etkisi
}

\author{
Murat Sami TÜRKER*
}

$\ddot{\mathbf{O} z}$

Temel dil becerilerinden biri olan okuma teknolojide yaşanan gelişmelerin etkisinde kalarak günümüzde ihmal edilen bir beceri durumuna gelmiştir. Son yıllarda eğitimciler, en önemli akademik becerilerden sayılan okumaya karşı öğrencileri isteklendirmek ve ders dışı okuma sürelerini artırabilmek için teknolojinin de işe koşulduğu yeni yöntemlerin arayışı içerisine girmişlerdir. Özellikle mobil cihazların günlük yaşamda yaygın olarak kullanılması, okuma becerisi öğretiminde "sesli kitaplar" için yeni uygulama alanlarını ortaya çıkarmıştır. Sesli kitapların yabancı dillerin öğretiminde okuma becerisine etkisi bugüne dek birçok çalışmaya konu olmuştur. Sesli kitapların yabancı dil olarak Türkçe öğrenenlerin okumaya yönelik tutumları üzerindeki etkisinin araştırıldığı bu çalışmanın da alana önemli katkılar sağlanacağı düşünülmektedir. Çalışma, B1 düzeyinde Türkçe öğrenen 21 yabancı uyruklu öğrencinin katılımıyla gerçekleştirilmiştir. Uygulama süresi sekiz hafta ile sınırlandırılan çalışma kapsamında, düzeye uygun olarak tercih edilen Türk edebiyatından seçme öyküler yazı ve ses dosyası biçiminde öğrencilere dağıtılmıştır. Çalışma öncesinde öğrencilerin okumaya yönelik tutumlarını belirleyebilmek amacıyla okuma tutum ölçeği uygulanmış, aynı ölçek sekiz haftalık uygulama sonunda tekrar uygulanarak sesli kitapların okumaya yönelik tutumlar üzerindeki etkisi araştırılmıştır. Çalışmadan elde edilen sonuçlar, öğrencilerin okumaya yönelik tutumlarında uygulama sonunda pozitif yönlü anlamlı bir değişim olduğunu ortaya koymuştur.

Anahtar Kelimeler: Yabancı dil olarak Türkçe öğretimi, okuma becerisi, sesli kitaplar, okuma tutumu.

\footnotetext{
* Öğr. Gör. Dr., Anadolu Üniversitesi, Yabancı Diller Yüksekokulu, Türkçe Öğretimi Araştırma ve Uygulama Merkezi, Eskişehir. Türkiye.

Elmek: muratsturker@gmail.com https://orcid.org/0000-0002-2037-8508
} 


\title{
The Effectiveness of Audio Books on Attitudes Reading by Learners of Turkish as a Foreign Language
}

\begin{abstract}
Reading, one of the basic language skills, has become a neglected skill today under the influence of developments in technology. In recent years, educators have been seeking technology-integrated new ways to encourage students to read and increase the length of extra-curricular reading. Especially, the widespread use of mobile devices in everyday life reveals new implementation areas for "audio books" in teaching reading skills. There have been several studies focusing on the effectiveness of audiobooks on reading skills in teaching foreign languages so far. This study, which investigates the effectiveness of audio books on attitudes towards reading by learners of Turkish as a foreign language, is believed to contribute to the field, as well.

The study was conducted with the participation of 21 foreign students who are learning Turkish at B1 level. Within the scope of the study, a selection of stories from Turkish literature were distributed to the students in the form of text and audio files throughout the eight-week implementation process. At the beginning of the study, a reading attitude scale was used to determine the students' attitudes towards reading, and the same scale was reapplied at the end of the implementation process to investigate the effectiveness of audio books on attitudes towards reading. The results of the study revealed that there was a significant positive change in the students' attitudes towards reading by the end of the study.
\end{abstract}

Keywords: Teaching Turkish as a foreign language, reading skill, audio books, reading attitudes. 


\section{Extended Summary}

It has long been agreed that reading in the first language is not a passive process, but an effective and interactive process. However, it was considered that reading in a foreign language was carried out by a passive, bottom-up method until recently. In order to understand the thought of the, the reader had to make sense of the idioms and phrases starting with the smallest written units, which are letters and words. In this respect, the main reason for reading problems in foreign language was based on understanding the written text. Later on, the idea that reading in a foreign language, as well as in the first language, depends on the experiences and background knowledge of the reader rather than knowing the language, word and meaning system (Carrell, Devine, and Eskey, 1988, pp. 1-3). In this top-down reading method, the aim of the reader and the expectations for the text directly affect the reading process (Grabe and Stoller, 2002, pp. 25, 26), and reading is accepted as an effort to construct an meaning based on the goals, cultural accumulation and experiences of the reader (Gunning, 2014, pp. 366-367).

One of the most important factors affecting the reading process is attitudes towards reading (Rubin and Opitz, 2007, p. 130). Since reading attitude affects the decision to read, individuals who have positive attitudes towards reading will read more and this will increase the reading success (Rubin and Opitz, 2007, pp. 130-132). For those who learn Turkish as a foreign language, as well as native language learners, developing positive attitudes towards reading will contribute significantly to the development of reading skills and other language skills. Therefore, besides academic knowledge and skills, the focus of reading instruction should be to gain positive attitudes towards reading. Given the interests and needs of today's students, audio books are effective tools that help students develop positive attitudes.

Audio books are one of the most effective learning tools that stimulate visual and auditory perception in foreign language teaching. However, previous studies on the use of audio books in teaching reading are mostly related to the teaching of other 
foreign languages, especially English, or they are conducted with participants from different age groups who have difficulty reading in mother tongue. In the area of teaching Turkish as a foreign language, it is noteworthy that there were not enough studies investigating the effect of audio books on reading instruction. It is thought that the results of this study will provide significant contributions to the field.

This study was designed according to the principles of hybrid learning model, enabling participants to choose between different learning areas inside and outside the school. 21 students who were learning Turkish as a foreign language in B1 level participated in the study and throughout the eight weeks implementation process, selected stories from Turkish literature were distributed to students in the form of writing and audio files. Each week, two stories were published in the blog, one of the stories was read and listened at the same time as a class activity at a pre-determined course time, and the other was read and listened individually by the students outside of the course hours.

At the beginning of the study, a reading attitude scale was used to determine the students' attitudes towards reading, and the same scale was reapplied at the end of the implementation process to investigate the effectiveness of audio books on attitudes towards reading.

At the end of the implementation, Paired Samples T-test was used to determine whether there is a statistically significant difference in students' attitudes towards reading. It is observed from the results that audio books promoted a positive change in students' attitudes towards reading $(\mathrm{p}<0.001)$. According to these results, there seems to be a significant change in the students' willingness to read ( $p<0.001)$ and their views on the benefits of reading $(p<0.001)$. At the end of the eight-week implementation period, it was also found that students' anxiety levels decreased significantly $(\mathrm{p}<0.001)$ and the value they give to reading increased significantly as well $(\mathrm{p}<0.001)$.

The results of the study indicate that simple technologies used in everyday life are an important factor that increases the interest towards learning. In this context, designing technology-mediated learning environments appropriate to student interests and needs should be a collaborative area for educators, material developers and program designers. 


\section{Giriş}

Önceleri yalnızca yazılı sembolleri tanımlamak olarak algılanan okuma kavramı (Wallace, 1996, s. 54), bugün okuyucunun metin ile etkileşim hâlinde etkin bir anlam çıkarma çabasını ifade etmektedir (Bursuck ve Damer, 2007, s. 252; Carnine, Silbert, Kame'enui, Tarver, ve Jungjohann, 2006, s. 22; Grabe ve Stoller, 2002, s. 9). Okuma, yazarın duygu ve düşüncelerine erişebilmek, aynı zamanda bu duygu ve düşünceleri tartışmak ve yargılamak demektir. Bu sebeple, okuma uğraşı düşünme sanatıyla iç içe geçmiş durumdadır. Okuma sanatını bilen birey, yazarla kendi arasında bağ kuran, metnin ardında gizlenen duygu ve düşünce dünyasını keşfeden insandır (Kayalan, 1992, ss. 18-19). Okuma, insanların bilgi birimini artıran, düşünme becerilerini ve dili kullanma yetisini geliştiren önemli bir araçtır. İnsanların yaşamında oldukça önemli bir yere sahip olan okuma, bilgiye ulaşmanın temel aracı olması yönüyle de en önemli akademik becerilerden biri olarak kabul edilmektedir (Grabe ve Stoller, 2001, s. 187).

Anadilde okumanın edilgin bir süreç değil, etkin ve etkileşimli bir süreç olduğu uzun süredir kabul edilmektedir. Ancak, yabancı dilde okumanın yakın zamanlara kadar edilgin, aşağıdan yukarıya bir yöntemle gerçekleştiği düşünülmekteydi. Okuyucu, yazarın anlatmak istediği düşünceyi anlayabilmek için en küçük yazılı birimler olan harfler ve sözcüklerden başlayarak daha büyük birimler olan deyimler ve cümleleri anlamlandırırdı. Yabancı dilde okuma problemlerinin temel nedeni de yazılı metni anlamaya dayanmaktaydı. Sonraları, yabancı dilde okumanın anadilde olduğu gibi dilin yazı, söz ve anlam sistemini bilmenin ötesinde okuyucunun geçmiş yaşantısına ve artalan bilgisine de bağlı olduğu görüşü ağırlık kazanmıştır (Carrell, Devine, ve Eskey, 1988, ss. 1-3). Yukarıdan aşağıya geçekleşen bu okuma yönteminde okuyucunun amacı ve metne yönelik beklentileri okuma sürecine doğrudan etki etmektedir (Grabe ve Stoller, 2002, ss. 25, 26). Buna göre okuma, okuyucunun amaçlarına, kültürel birikimine ve deneyimlerine dayanarak etkin bir anlam yapılandırma uğraşı olarak kabul edilmektedir (Gunning, 2014, ss. 366-367). Kişi mevcut bilgileriyle yeni öğrendiklerini ilişkilen- 
direbildiği ölçüde kavrama gerçekleşir. Bunun için kişinin zihninde var olan ve şema olarak adlandırılan artalan bilgisi ne kadar zengin ise kavrama aynı ölçüde kolay ve çabuk olur (Almasi, 2003, s. 75).

Öğrencilerin ne okuyacă̆ı, nasıl okuyacă̆ı ve okudukları metne nasıl tepki vereceği onların ilgileri, yaşamları ve gerçek dünyayla ilişkili olmalı, diğer bir ifadeyle özgün olmalıdır. Ancak okuma sürecinin özgün olması etkili bir okuma deneyimi için tek başına yeterli değildir. Öğrencilerin okuma sürecine istekli bir şekilde katılmaları da onların okumak için harcadıkları süreye etki edeceğinden önemlidir. Bu bağlamda özgün okuma, okuma isteği ve harcanan süre ile okuma düzeyi arasında karşılıklı bir ilişki söz konusudur (Rasinski ve diğerleri, 2010, s. 2). Öğrencileri okul dışında ve ödevleri haricinde kendi başlarına ve isteyerek okumaya yönlendirmek için öğretmenlere büyük görevler düşmektedir. Öğrenci ilgi ve ihtiyaçlarına uygun kitap seçme, düzenli okumayı teşvik etme, başarıyı ödüllendirme, farklı okuma yöntemleri öğretme, kitaplar hakkında paylaşımda bulunabilecek ortam hazırlama öğretmenin sorumluluklarından bazılarıdır (Johnson, 2016, ss. 110-114).

Okuma sürecini etkileyen diğer önemli bir etken okumaya yönelik tutumlardır (Rubin ve Opitz, 2007, s. 130). Tutum, genel olarak insanın herhangi bir olay ya da durum karşısında olası bir tavır ya da davranış biçimini oluşturma eğilimidir (İnceoğlu, 2011, s. 13). Kişinin zihnindeki somut nesnelere ya da soyut olgulara karşı tepkisel eğilimini ifade eden tutumlar (Bohner ve Weanke, 2002, ss. 4-5), karakteristik özellikler gibi varsayımsal bir kurgudur, doğrudan gözlemlenemez ancak ölçülebilir tepkilerden anlaşılabilir (Ajzen, 2005, s. 3). DemirtaşMadran'a (2012) göre tutumlar öğrenilir, her ne kadar kalıcı ve değişime dirençli olsalar da değiş̧ebilir. Bireylerin duygusal, bilişsel, davranışsal özellikleri ve deneyimleri ile içinde bulunulan eylemin gidişatı tutumların değişmesine etki eden unsurlardır (İnceoğlu, 2011, ss. 25, 28).

Tutumlar motivasyona, motivasyon da insanların başarı ya da başarısızlık algısına etki eder. Art arda başarısız olan insanlar kendilerini başarılı olabilecek yeterlikte görmemeye başlarlar. Dahası, bu insanlar öğrenilmiş çaresizlik hissine kapılabilir ve başaramayacakları kanaatine varabilirler. Oysaki öğrenilmiş çaresizlik değiştirilebilir bir durumdur. Diğer bir ifadeyle, akıcı şekilde okuyamaya- 
cağını düşünen öğrenciler sonrasında etkin okuyucular olacakları inancına sahip olabilirler (Rasinski ve diğerleri, 2010, s. 58). Bu nedenle, akademik bilgi ve becerilerin yanı sıra, okuma öğretiminin temel amaçlarından biri de okumaya karşı olumlu tutumlar kazandırmak olmalıdır.

Okuma tutumu; az ya da çok okumaya neden olan, duyguların da etki ettiğ $i$ zihinsel durum olarak tanımlanabilir (Smith, 1990, s. 215). Okuma tutumu bireyin okuma ile ilgili kararını etkileyeceği için okumaya karşı olumlu tutuma sahip olan bireyler daha fazla okuyacak, bu da beraberinde okuma başarısını artıracaktır (Rubin ve Opitz, 2007, ss. 130-132). Anadil öğrenenler gibi Türkçeyi yabancı dil olarak öğrenenlerin de okumaya karşı olumlu tutum geliştirmeleri, okuma becerilerinin ve buna bağlı olarak diğer dil becerilerinin gelişimine önemli katkılar sağlayacaktır.

Teknolojiyle iç içe yaşamlar süren bugünün öğrencilerini okul sınırları dışında ve ödev haricinde okumaya yönlendirmek pek de kolay olmamaktadır. Son y1llarda eğitimciler, zamanlarının büyük bölümünü Facebook, Twitter ya da bloglar gibi sosyal paylaşım ağlarında geçiren öğrencilerin okuyarak geçirdikleri süreyi ve okuma sıklığını artırabilmek için yeni öğretim yöntem ve araçlarının arayışı içerisine girmişlerdir. Dilin edebî kullanımına örnekler sunan, görsel ve işitsel algıyı eşzamanlı harekete geçirerek okumayı/kavramayı kolaylaştıran ve okumayı keyifli bir etkinliğe dönüştüren yöntemlerden biri de sesli kitaplar arac1lığıyla uygulanan sesli okuma yöntemidir.

Yazı dili ve konuşma dili arasındaki en büyük fark yazı dilinin konuşma dili kadar bağlamsal zenginliklere sahip olmamasıdır. Diğer bir ifadeyle, yazı dilinde yazarın ve okurun aynı fiziksel ortamı paylaşmaları beklenmez. Bu sebeple, yazar anlam bütünlüğünü sağlamak için noktalama işaretleri, tutarlılık, bağdaşıklık gibi çok sayıda yazınsal ipuçlarından faydalanır. Okuyucular, metinden anlam çıkarmak için bu ipuçlarının farkında olmalı ve metinde yer alan bilgileri anlamlı bir biçimde ilişkilendirebilmelidir (Lipson ve Wixson, 2013, s. 320). Oysa sözel kullanımda, sesletim, tonlama, vurgu, duraklama gibi eylemler anlamayı kolaylaştırmaktadır. Bu bağlamda, sesli kitap okuma oldukça faydalı bir yöntemdir.

Okuma güçlüğü yaşayan öğrenciler ya yazılı sözcükleri okumakta zorlanırlar, ya okuduklarını kavrama konusunda çok iyi değillerdir, ya da akıcı okuya- 
madıklarından problem yaşarlar (Johnson, 2016, s. 155). Sesli kitap okuma öğrencilere kelime dağarcığını geliştirme, edebî dili anlama, dilbilimsel farkındalığı artırma, hikâyenin akışını ve gelecek olayları tahmin edebilme, metni daha iyi anlama ve hatırlama gibi çok sayıda fayda sağlayarak okuma problemlerinin önüne geçer (Lipson ve Wixson, 2013, ss. 320-321). Okuma becerisinin gelişimine önemli ölçüde katkı sağlayan sesli okuma, aynı zamanda kafiye, ses tekrarı, ses değişimi ve ses bölünmesi gibi dil özelliklerini ön plana çıarak öğrencilerin sesbilimsel farkındalıklarını artırır (Rubin ve Opitz, 2007, ss. 16, 169), dilin özgün kullanımına örnekler sunarak yeni kavramların ve yeni yapıların öğrenilmesini kolaylaştırır, bu sayede dili kullanabilme yetisinin ve diğer dil becerilerinin gelişimine katk1 sağlar (Jennings, Caldwell, ve Lerner, 2006, ss. 140, 162).

Dil öğretiminde sesli kitapların kullanımı ile ilgili bugüne dek yürütülmüş çok sayıda çalışmaya rastlamak mümkündür. Taguchi, Takayasu-Maass, ve Gorsuch (2004) yürüttükleri çalışmanın sonucu olarak sesli kitapların görsel ve işitsel ögeleri aynı anda sunan ve okumayı eğlenceli bir deneyime dönüştüren araçlar olduğunu ifade etmişlerdir. Esteves ve Whitten (2011) tarafindan yürütülen bir başka çalışma, sesli kitap okuyan deney grubu öğrencilerinin yalnızca basılı kitap okuyan kontrol grubu öğrencilerinden daha akıcı okudukları sonucunu ortaya koymuştur. Benzer bir çalışma (Friedland, Gilman, Johnson, ve Demeke, 2017), sesli kitaplarla yap1lan okuma etkinliklerinin okuma hızını artırdığı sonucunu desteklemektedir. Türker (2010) çalışmasında, sesli kitapların okuma becerisi üzerindeki etkisini farklı yeterlik düzeyleri bağlamında araştırmış, bir ders dışı etkinlik olarak uygulanan sesli kitap okuma etkinliklerinin temel ve orta düzeyde okuma başarısını artırdığ ve okumaya yönelik tutumları olumlu yönde etkilediği sonucuna ulaşmıştır. Wagar (2016) çalışmasında, sesli kitapların kavrama becerisini artırdığı ve öğrencileri okumaya karşı isteklendirdiği sonucunu ortaya koymuştur.

\section{Amaç}

Teknoloji alanında yaşanan gelişmeler ve dijital yerlilerin teknolojiyi kullanma konusundaki üstün yetenekleri eğitimde de teknoloji kullanımını bir zorunluluk hâline getirmiştir. Sosyal yaşamı etkisi altına alan bilgi ve iletişim teknolojilerinin eğitimde kullanım alanlarının artması ve "z kuşağı" olarak adlandırılan 
günümüz neslinin değişen ilgi ve gereksinimleri mevcut öğrenme ortamlarının ve öğretim malzemelerinin yeniden tasarlanması gereksinimini ortaya çıkarmıştır. Bu doğrultuda geliştirilen "Çoklu-Ortamlı Öğrenme” modeline göre bilgi görsel ve işitsel verilerle desteklenerek birden fazla ortamda sunulduğunda öğrenme daha etkili ve kalıcı olur (Mayer, 2009, s. 4).

Sesli kitaplar, yabancı dil öğretiminde görsel ve işitsel algıyı harekete geçiren etkili öğrenme araçlarından biridir. Başta İngilizce olmak üzere birçok dilin öğretiminde bu bilinçle hazırlanmış sayısız eserler bulunmaktadır. Türkçeyi yabancı dil olarak öğrenenler için İnce ve Güleç (2018) tarafından hazırlanan Türk Edebiyatı Antolojisi ve Deniz Kültür Yayınları tarafından hazırlanan Sesli Edebiyat Dizisi-1 (2007), Sesli Edebiyat Dizisi-2 (2009) Türkçenin ve Türk kültürünün öğretiminde başvurulabilecek kaynak eserlerdir.

Alanyazın incelendiğinde, okuma öğretiminde sesli kitapların kullanımı ile ilgili çalışmalara rastlanmaktadır. Ancak bu çalışmaların çoğunlukla İngilizce başta olmak üzere diğer yabancı dillerin öğretimi ile ilgili olduğu ya da anadilde okuma güçlügü çeken farklı yaş gruplarından katılımcılarla yürütüldüğü görülmektedir. Yabancı dil olarak Türkçe öğretimi alanında ise sesli kitapların okuma öğretiminde etkisini araştıran kapsamlı bir çalışmaya rastlanmamış olması dikkat çekmektedir. Bu çalışmadan elde edilen sonuçların söz konusu ihtiyaca yönelik önemli katkılar sağlayacağı düşünülmektedir.

\section{Yöntem}

Sesli kitapların yabancı dil olarak Türkçe öğrenen üniversite öğrencilerinin okumaya yönelik tutumları üzerindeki etkisini araştırmak amacıyla yürütülen bu çalışma, karma (hibrid) öğrenme modelinin ilkeleri bağlamında katılımcıların okul içi ve okul dışı farklı öğrenme alanları arasında tercih yapmalarına olanak sağlayacak şekilde tasarlanmıştır. Türk edebiyatçıları tarafından kaleme alınmış ve ünlü tiyatrocular tarafından seslendirilmiş öykülerin sekiz haftalık uygulama süresince katılımcılarla paylaşıldığı çalışma kapsamında yanıt aranan araştırma sorusu aşağıdaki gibidir:

- Sesli kitapların yabancı dil olarak Türkçe öğrenenlerin okumaya yönelik tutumları üzerindeki etkisi nedir? 
Veri toplama araçlarının uygulanışı ve veri analiz yöntemleri bağlamında nicel bir araştırma olan çalışmanın verileri, okumaya yönelik tutumların ölçüldügü okuma tutum ölçeğinin çalışma öncesi ve çalışma sonrası uygulanması sonucu elde edilmiştir. Elde edilen veriler "SPSS 22.0" (Statistical Package for The Social Sciences) yazılım programı kullanılarak ilgili araştırma sorusu bağlamında analiz edilmiştir.

\section{1. Çalışma Grubu}

Çalışma, Anadolu Üniversitesi TÖMER ${ }^{1}$ 'de yabancı dil olarak Türkçe öğrenen ve 2017-2018 akademik yılı güz döneminde Anadolu Üniversitesi TÖMER tarafindan yapılan seviye belirleme sınavı sonuçlarına göre B1 düzeyine devam eden 21 öğrencinin katılımıyla gerçekleştirilmiştir. Lisans ve lisansüstü düzeyde eğitim almak için 13 farklı ülkeden Türkiye'ye gelen katılımcılara ait bilgiler Tablo 1 'de gösterilmektedir.

Tablo 1. Çalışmanın katılımcıları

\begin{tabular}{|c|c|c|c|}
\hline Özellikler & Kategoriler & $\mathbf{N}$ & \% \\
\hline \multirow{2}{*}{ Yaş } & $16-18$ & 9 & 42.8 \\
& $19-21$ & 6 & 28.5 \\
& $22-24$ & 5 & 23.8 \\
& $25-27$ & 1 & 4.7 \\
Eğittim & Lisans & 13 & 61.9 \\
& Y. Lisans & 5 & 23.8 \\
& Doktora & 3 & 47.2 \\
\hline \multirow{2}{*}{ Cinsiyet } & Erkek & 10 & 52.3 \\
\hline
\end{tabular}

1 Türkçe Öğretimi Uygulama ve Araştırma Merkezi 
Çalışma, mevcut müfredat programını destekleyici nitelikte ek bir öğrenme ortamı sunarak okul içi ve okul dışı farklı öğrenme alanlarında yürütülecek şekilde tasarlandığından çalışmaya katılan öğrencilerin öğretmenlerinden bağımsız olarak etkinliklere katılmaları sağlanmıştır. Bu nedenle, genel dil yapılarını bilen, anlaşılır ve ölçünlü bir dil kullanıldığında günlük dilde sık kullanılan sözcükleri içeren metinleri ya da konuşmaları anlayabilecek yeterlikte olan (Avrupa Konseyi, 2013, s. 31) B1 düzeyinden² öğrenciler tercih edilmiştir.

\subsection{Veri Toplama Araçları}

Çalışma öncesinde, araştırmacı tarafindan Wordpress altyapısı kullanılarak özgün bir blog sitesi tasarlanmış, çalışmada kullanılacak olan sesli öyküler blog sitesi üzerinden öğrencilerle paylaşılmıştır. "Öyküler Konuşuyor" adı ile erişim sağlanan blogda, çalışmada kullanılmak üzere tercih edilen öykülere ait ses ve yazı dosyalarının paylaşıldığı “Öykü Kitaplığı” bölümü, öğrencilerin gereksinim hâlinde başvurabilecekleri 12 dilde hazırlanmış "Sözlükler" bölümü, son olarak da çalışma ile ilgili bilgilendirmelerin yapıldığı "Duyurular" bölümü yer almaktadır. Blog sitesinin, görünüm ve teknik özellikler bakımından değerlendirilebilmesi amacıyla Bilgisayar ve Öğretim Teknolojileri Eğitimi bölümünden iki uzmanın görüşlerine başvurularak gerekli düzenlemeler uygulama öncesinde tamamlanmıştır. Blog sitesinin ana ekran görüntüsü Resim 1'de gösterilmektedir.

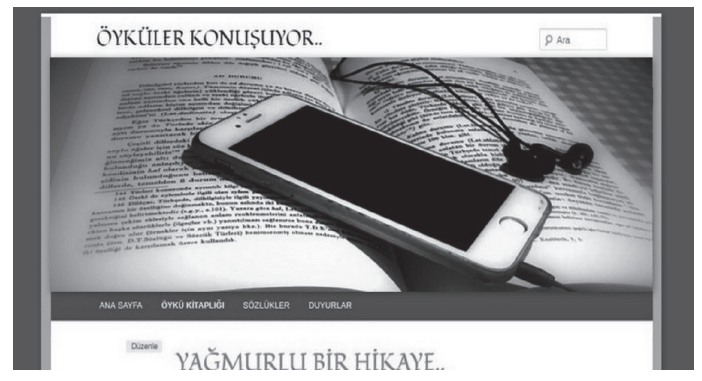

Resim 1. Blog sitesi ana ekran görüntüsü 
Çalışma kullanılan öykülerin belirlenmesinde iki ölçüt temel alınmıştır. Bunlardan ilki öykülerin kavramsal yoğunluğu, diğeri ise öykülerin uzunluğudur. Bu bağlamda, içerdiği sözcük ve dil bilgisi yapıları açısından B1 düzeyine uygun ve kayıt uzunluğu 8-16 dakika arasında değişen öyküler tercih edilerek öğrencilerin her hangi bir kaynak kitaba başvurmadan ve ilgileri dağılmadan etkinliklere katılabilmeleri amaçlamıştır. Yabancılara Türkçe öğreten 4 öğretim elemanının görüşleri alınarak tercih edilen öyküler bağlamında gerekli değişiklikler yapılmıştır (Bkz. Tablo 2).

Tablo 2. Çalışmada kullanılan sesli öyküler

\begin{tabular}{llll}
\hline \multicolumn{1}{c}{ Yazar } & \multicolumn{1}{c}{ Öykü } & $\begin{array}{c}\text { Sözcük } \\
\text { Sayısı }\end{array}$ & $\begin{array}{c}\text { Süre } \\
\text { (dk) }\end{array}$ \\
\hline Cahit Sıtkı Tarancı & Abbas & 1461 & 13.35 \\
\hline Orhan Kemal & Çikolata & 1194 & 11.45 \\
\hline Reşat Nuri Güntekin & Kirazlar & 1341 & 13.22 \\
\hline Sait Faik Abasıyanık & Plajdaki Ayna & 1893 & 16.06 \\
\hline Ziya Osman Saba & Mesut İnsanlar Fotoğrafhanesi & 1543 & 16.43 \\
\hline Cevat Şakir Kabaağaçlı & Tünek Ahmet & 1175 & 12.43 \\
\hline Sait Faik Abasıyanık & Yağmurlu Bir Hikâye & 768 & 09.45 \\
\hline Orhan Veli Kanık & İşsizlik & 1184 & 11.40 \\
\hline Oğuz Atay & Demiryolu Hikâyecileri (1. Bölüm) & 1344 & 12.21 \\
\hline Oğuz Atay & Demiryolu Hikâyecileri (2. Bölüm) & 1331 & 12.30 \\
\hline Sait Faik Abasıyanık & Hişt Hişt & 683 & 08.04 \\
\hline Murat Çabas & Kinalı Ali & 675 & 09.50 \\
\hline Adalet Ağaoğlu & Karanfilsiz & 1037 & 11.54 \\
\hline Anton Çehov & Memurun Ölümü & 654 & 06.39 \\
\hline Sait Faik Abasıyanık & Yandan Çarklı & 1297 & 09.44 \\
\hline Aziz Nesin & Biz Adam Olmayız & 10.10 \\
\hline & & 647 & 139 \\
\hline
\end{tabular}


Bloğun öne çıkan özelliklerinden biri de tablet bilgisayarlar ve akıllı telefonlar gibi taşınabilir cihazlar üzerinden kullanılabilir şekilde tasarlanmış olmasıdır. Böylelikle, öğrencilere diledikleri yerden ve diledikleri zaman öyküleri okuyabilme ve dinleyebilme olanağ 1 sağlanmıştır. Ayrıca, uygulama süresince öğrenciler arasında okul dışı iletişimi ve etkileşimi sağlamak amacıyla blogda paylaşılan öykülerin altına bir yorum bölümü eklenerek öğrencilerin okudukları ve dinledikleri öykülerle ilgili paylaşımda bulunmalarına olanak sağlanmıştır.

Nicel bir araştırma olan çalışmanın verileri çalışma öncesi ve çalışma sonrası uygulanan okuma tutum ölçeğinden elde edilmiştir. Rashtchi ve Hajihassani (2010) tarafindan geliştirilen ölçek özgün dili olan İngilizceden Türkçeye çevrildikten sonra Türkçe öğrenen 89 yabancı uyruklu öğrenciyle bir pilot çalışma yapılmış, elde edilen verilerle ölçeğin güvenirlik ve faktör analizleri yapılmıştır. Yapılan analizler sonucu, Likert tipi hazırlanan ve 30 maddeden oluşan ölçeğin dört faktörlü (istek, fayda, kayg1 ve değer algısı) bir yapıya sahip olduğu ve oldukça güvenilir olduğu tespit edilmiştir $(\alpha=0.916)$.

\subsection{Uygulama Süreci}

Çalışma öncesinde öğrencilerle bir tanıtım toplantısı düzenlenerek uygulama süreci ve blog sitesi ile ilgili bilgilendirmeler yapılmışıtır. Uygulama süreci sekiz hafta olarak planlanan çalışma öncesinde öğrencilerin okumaya yönelik tutumlarının belirlenebilmesi amacıyla blog tutum ölçeği uygulanarak ön-test verileri elde edilmiştir. Takip eden sekiz hafta boyunca her hafta iki öykü blogda yayımlanmış, öykülerden biri önceden belirlenen bir ders saatinde sınıf içi etkinlik olarak aynı anda okunmuş ve dinlemiş, diğeri ise ders saatleri dışında öğrenciler tarafından bireysel olarak okunmuş ve dinlenmiştir. Sekiz haftalık uygulama sürecinin ardından blog tutum ölçeği tekrar uygulanarak son-test verileri elde edilmiş, öğrencilerin okumaya yönelik tutumlarında olası değişikliklerin belirlenebilmesi amaciyla ön-test ve son-test verileri SPSS 22.0 (Statistical Package for the Social Sciences) programı kullanılarak analiz edilmiştir.

\section{Bulgular}

Sekiz haftalık uygulama sürecine sahip olan çalışmanın verileri, uygula- 
ma öncesinde Türkçeye uyarlanan ve yapılan analizler sonucunda dört faktörlü (istek, fayda, kaygı ve değer algısı) bir yapıya sahip olduğu belirlenen okuma tutum ölçeğinden elde edilmiştir. Ölçek, öğrencilerin okumaya yönelik mevcut tutumlarının belirlenebilmesi amacıyla çalışma öncesinde uygulanarak ön-test verileri elde edilmiş, sesli kitapların öğrencilerin tutumları üzerindeki olası etkisini tespit edebilmek amacıyla da çalışma sonunda uygulanarak son-test verileri elde edilmiştir. Ölçekten elde edilen verilerin istatistiksel analizlerine geçmeden önce verilerin normal dağılıp dağılmadığ "Normal Dağılım Testi" ile araştırılmıştır. Normal dağılım gösterdiği belirlenen veriler için parametrik istatistik yöntemleri kullanılarak analizler yapılmıştır. Ön-test ve son-test olarak uygulanan okuma tutum ölçeğinden elde edilen verilerin aritmetik ortalaması ve standart sapmaları hesaplanmış sonuçlar Tablo 3 'te gösterilmiştir.

Tablo 3. Okuma tutum ölçeği betimsel istatistik verileri

\begin{tabular}{|c|c|c|c|c|c|}
\hline & Madde & $\bar{X}$ & $\mathbf{N}$ & Ss & $\mathbf{S} \overline{\mathbf{x}}$ \\
\hline \multirow{5}{*}{ Uygulama Öncesi } & İstek & 2.85 & 21 & 0.31802 & 0.069 \\
\hline & Fayda & 3.08 & 21 & 0.25727 & 0.056 \\
\hline & Kayg1 & 2.38 & 21 & 0.32544 & 0.071 \\
\hline & Değer Algis1 & 3.03 & 21 & 0.20227 & 0.044 \\
\hline & OTÖ Toplam & 2.90 & 21 & 0.14369 & 0.031 \\
\hline \multirow{5}{*}{ Uygulama Sonrası } & İstek & 3.48 & 21 & 0.37232 & 0.081 \\
\hline & Fayda & 3.48 & 21 & 0.40222 & 0.087 \\
\hline & Kayg1 & 3.29 & 21 & 0.28037 & 0.061 \\
\hline & Değer Algısı & 3.50 & 21 & 0.35168 & 0.076 \\
\hline & OTÖ Toplam & 3.46 & 21 & 0.30978 & 0.067 \\
\hline
\end{tabular}

Tablo 3'teki sonuçlar, çalışma öncesi ve çalışma sonrası uygulanan ölçekten elde edilen veriler arasında dikkate değer farklar olduğunu göstermektedir. Uygulama sonucunda öğrencilerin okumaya yönelik tutumlarında gözlemle- 
nen bu değişimin istatistiksel olarak anlamlı olup olmadığının belirlenebilmesi amacıyla "İlişkili Örnekler için T-testi” (Paired Samples T-test) kullanılmış, anlamlılık düzeyi 0.05 kabul edilerek sonuçlar yorumlanmıştır. Sonuçlar Tablo 4'te gösterilmektedir.

Tablo 4. Okuma tutum ölçeği (ön-test \& son-test) ilişkili örnekler için t-testi sonuçları

\begin{tabular}{|c|c|c|c|c|c|c|c|c|}
\hline & & & $\overline{\mathbf{X}}$ & Ss & $\mathbf{S} \overline{\mathbf{x}}$ & $t$ & $\mathbf{N}$ & $\begin{array}{c}p(i k i \\
\text { yönlü) }\end{array}$ \\
\hline İstek 1 & - & İstek 2 & -0.62773 & 0.39613 & 0.08644 & -7.262 & 21 & 0.000 \\
\hline Fayda_1 & - & Fayda_2 & -0.39622 & 0.45824 & 0.10000 & -3.962 & 21 & 0.001 \\
\hline Kayg1_1 & - & Kayg1_2 & -0.90525 & 0.49195 & 0.10735 & -8.432 & 21 & 0.000 \\
\hline Değer_1 & - & Değer_2 & -0.47343 & 0.30339 & 0.06621 & -7.151 & 21 & 0.000 \\
\hline ÖTÖ_1 & - & OTÖ_2 & -0.55824 & 0.31918 & 0.06965 & -8.015 & 21 & 0.000 \\
\hline
\end{tabular}

Tablo 4’teki sonuçlara bakıldığında, sesli kitapların öğrencilerin okumaya yönelik tutumlarında olumlu yönde anlamlı bir değişime neden olduğu göze çarpmaktadır, $p<0.001$. Bu sonuçlara göre, sekiz haftalık uygulama süreci sonunda öğrencilerin okumaya karşı daha istekli oldukları yönünde anlamlı bir değişim olduğu görülmektedir, $p<0.001$. Sesli kitapların, öğrencilerin okumanın faydalarına ilişkin görüşlerinde de olumlu yönde anlamlı bir değişime neden olduğu Tablo 3 'te açıkça görülmektedir, $p<0.001$. Bu sonuçlara göre öğrencilerin, okumaya yönelik tutumların alt boyutu olan kaygı düzeylerinin uygulama sonunda anlamlı oranda azaldığı, $p<0.001$; okumaya verdikleri değerin de uygulama sonunda anlamlı oranda arttığı anlaşılmaktadır, $p<0.001$. Ölçeğin istek alt boyutuna ilişkin sonuçlar Tablo 5 'te gösterilmektedir. 
Tablo 5: Okuma tutum ölçeği "İstek” alt boyutu, ilişkili örnekler için t-testi sonuçları

\begin{tabular}{|l|c|c|c|c|c|}
\hline İstek & $\overline{\mathbf{X}}$ & $\mathbf{S s}$ & $\boldsymbol{t}$ & $\mathbf{N}$ & $\begin{array}{c}\boldsymbol{p} \text { (iki } \\
\boldsymbol{y} \boldsymbol{o ̈ n} \mathbf{n i})\end{array}$ \\
\hline 1. Türkçe okumak eğlencelidir. & $-0,669$ & 0,759 & $-4,034$ & 21 & 0,001 \\
\hline 2. Türkçe okumay1 severim. & $-0,308$ & 0,773 & $-1,829$ & 21 & 0,082 \\
\hline 3. Türkçe okumak sıkıcıdır. & $-0,346$ & 0,629 & $-2,521$ & 21 & 0,020 \\
\hline $\begin{array}{l}\text { 8. Türkçe okumak zevklidir. } \\
\text { 14. Okuma beni heyecanlan- } \\
\text { dırır. }\end{array}$ & $-0,388$ & 0,756 & $-2,354$ & 21 & 0,029 \\
\hline $\begin{array}{l}\text { 15. Okuma metinleri genelde } \\
\text { bitirilecek kadar iyi değildir. }\end{array}$ & $-1,285$ & 0,911 & $-6,465$ & 21 & 0,000 \\
\hline $\begin{array}{l}\text { 29. Okuma derslerinde çok } \\
\text { rahatım. }\end{array}$ & $-0,725$ & 0,685 & $-4,850$ & 21 & 0,000 \\
\hline
\end{tabular}

Sonuçlar, sekiz haftalık uygulama sonunda öğrencilerin okumaya karş1 daha istekli oldukları yönünde anlamlı bir değişim olduğunu göstermektedir. 1'inci, 2'inci ve 14'üncü maddeler değerlendirildiğinde, sesli kitap uygulamasının ardından öğrencilerin okumaya karşı güdülenme oranlarında bir artış olduğu göze çarpmaktadır. 3'üncü ve 8 'inci maddelerde okuma sürecinin sesli kitapların etkisiyle sıkıcı olmaktan çıkarak keyifli bir etkinliğe dönüştüğü görülmektedir. Okuma metinlerinin uzunluğu ve etkinliklere katılım ile ilgili olan 15'inci ve 29'uncu maddelerde öğrencilerin görüşlerinde anlamlı farklar olduğu görülmektedir. Sesli kitapların belli bir akış ve ahenk içerisinde öğrencileri okumaya yönlendirmesinin yapı bilgisi, sözcük bilgisi ve anlam bilgisi gibi konularda yetkinlik düzeyi düşük olan öğrencilerin okuma isteklerini ve özgüvenlerini artırıcı bir etken olduğunu söylemek mümkündür.

Öğrencilerin okumanın yararlarına ilişkin inançları ölçeğin ikinci alt boyutu olarak incelenmiş, sonuçlar Tablo 6' da gösterilmiştir. 
Tablo 6: Okuma tutum ölçeği "Fayda / İnanç" alt boyutu, ilişkili örnekler için t-testi sonuçları

\begin{tabular}{|l|c|c|c|c|c|}
\hline Fayda / İnanç & $\overline{\mathbf{X}}$ & $\mathbf{S s}$ & $\boldsymbol{t}$ & $\mathbf{N}$ & $\boldsymbol{p}$ (iki yönlü) \\
\hline $\begin{array}{l}\text { 7. Okuma, günlük yaşam etkin- } \\
\text { likleri ile ilişkili olmalıdır. } \\
\text { 16. Okumanın bana fayda sağla- } \\
\text { yacağına inanıorum. }\end{array}$ & $-0,589$ & 0,901 & $-2,993$ & 21 & 0,007 \\
\hline $\begin{array}{l}\text { 19. Okuma sözcük bilgimi artır- } \\
\text { mama yardımcı olur. }\end{array}$ & $-0,068$ & 0,774 & $-0,403$ & 21 & 0,692 \\
\hline $\begin{array}{l}\text { 20. Okuma, diğer dil becerilerini } \\
\text { geliştirmeme yardımcı olur. }\end{array}$ & $-0,406$ & 1,118 & $-1,662$ & 21 & 0,112 \\
\hline $\begin{array}{l}\text { 21. Dil bilgisi hakkında bildikle- } \\
\text { rimi okuyarak geliştirebilirim. }\end{array}$ & $-0,138$ & 1,142 & $-0,554$ & 21 & 0,586 \\
\hline $\begin{array}{l}\text { 22. Türkçede okumanın kolay } \\
\text { bir iş olduğunu düşünüyorum. }\end{array}$ & $-0,907$ & 1,139 & $-3,649$ & 21 & 0,002 \\
\hline $\begin{array}{l}\text { 24. Okuma, eleştirel düşünme } \\
\text { becerilerimi geliştirir. }\end{array}$ & $-0,635$ & 0,838 & $-3,473$ & 21 & 0,002 \\
\hline $\begin{array}{l}\text { 27. Okuma, diğer kültürleri } \\
\text { tanımamıza yardımcı olur. }\end{array}$ & $-0,217$ & 0,713 & $-1,394$ & 21 & 0,179 \\
\hline $\begin{array}{l}\text { 30. Okuma, herkesin öğrenmesi } \\
\text { gereken önemli becerilerden } \\
\text { biridir. }\end{array}$ & $-0,403$ & 0,577 & $-3,196$ & 21 & 0,005 \\
\hline
\end{tabular}

Ölçeğin ikinci alt boyutundan elde edilen sonuçlar, okumanın öğrencilere çeşitli alanlarda sağlayacağı yararlara ilişkin inançları ortaya koymaktadır. 7'inci, 16'nncı ve 30'uncu maddeler okumanın günlük yaşam ve gelecek üzerindeki etkisine ilişkin öğrencilerin düşüncelerinde olumlu yönde anlamlı bir değişim olduğunu göstermektedir. 19'uncu, 20'nci ve 21'inci maddelerde ise okumanın yabancı dil öğrenimine katkısı araştırılmış, ancak uygulama öncesi ve uygulama sonrası verilerde anlamlı bir farka rastlanmamıştır. Okumaya yönelik istekleri ya da beceri düzeyleri değişse de okumanın dil öğrenimdeki önemi ile ilgili dünya bilgileri ve okuma güçlüklerinin dil öğrenme sürecini doğrudan etkilemesi uygulama öncesinde de öğrencelerin bu maddelere ilişkin inanç düzeylerinin yüksek olmasının nedeni olarak değerlendirilebilir. Benzer şekilde, 27'inci maddede okumanın kültürel etkileşime olan etkisi konusunda da ön test ve son test verileri arasından anlamlı bir fark çıkmaması öğrencilerin anadilde okuma deneyimle- 
rinin etkisi ile açıklanabilir. Yabancı dilde olduğu gibi anadilde de okuma farklı kültürleri tanımanın en etkili yollarındandır. Yapısı gereği sesli kitapların belli akış hızı ile okumaya yönlendirmesi, okumanın kolaylığı konusunda öğrencilerin 22'inci maddeye ilişkin inançlarındaki değişimin nedeni olarak gösterilebilir. Yaz1l metnin ortam sesleriyle desteklenmesi ve seslendirmelerin vurgular ve tonlamalarla zenginleştirilmesi gibi teknik özellikleri, sesli kitapların metne yönelik eleştirel bakış açısını geliştirdiği yönünde 24'üncü maddede görülen anlamlı farkın açıklayıcısı olabilir.

Ölçeğin üçüncü alt boyutu sesli kitapların öğrencilerin okuma kaygıları üzerindeki etkisi ile ilgili detaylı bilgi vermeyi amaçlamaktadır. Sonuçlar, Tablo 7'de gösterilmektedir.

Tablo 7: Okuma tutum ölçeği "Kaygı” alt boyutu, ilişkili örnekler için t-testi sonuçları

\begin{tabular}{|l|c|c|c|c|c|}
\hline Kaygı & $\overline{\mathbf{X}}$ & $\mathbf{S s}$ & $\boldsymbol{t}$ & $\mathbf{N}$ & $\boldsymbol{p}$ (iki yönlü) \\
\hline 6. Okumak zaman alan bir iştir. & $-1,273$ & 0,950 & $-6,142$ & 21 & 0,000 \\
\hline $\begin{array}{l}\text { 11. Okuma, eğlenmek için değil } \\
\text { öğrenmek içindir. }\end{array}$ & $-0,447$ & 0,846 & $-2,423$ & 21 & 0,025 \\
\hline $\begin{array}{l}\text { 25. Gündelik hayatta okuma önemli } \\
\text { bir yere sahip değildir. }\end{array}$ & $-0,418$ & 0,806 & $-2,375$ & 21 & 0,028 \\
\hline $\begin{array}{l}\text { 26. Okuma beni endişelendirir. } \\
\begin{array}{l}\text { 28. Okuma derslerine katılma konu- } \\
\text { sunda istekli değilim. }\end{array}\end{array}-1,024$ & 0,900 & $-5,214$ & 21 & 0,000 \\
\hline
\end{tabular}

Tablo 7'deki sonuçlar değerlendirildiğinde 6'incı, 26'ıncı ve 28'inci maddelerde görülen anlamlı farkın, sesli kitapların okumada akıcılığı artırarak zaman kaygısını azalttığı, okuma hızına bağlı olarak da öğrencilerin okuma ile ilgili endişelerinin azaldığı ve derse katılım sıklığının arttı̆̆ yönünde açıklanması mümkündür. Okumanın rolüne ilişkin öğrencilerin uygulama öncesi ve uygulama sonrası görüşlerinde, 11 'inci maddeden de anlaşlldığ 1 üzere anlamlı bir farka rastlanmamıştır. Öğrencilerin, özellikle akademik ortamlarda okumayı öğrenmeyle ilişkilendirmeleri ve okuma güçlüklerinin öğrenememe durumuna yol açacağ endişesi bu kaygının bir nedeni olabilir. Okumanın, yabancı dilde olduğu gibi anadilde de günlük yaşamda önemli bir yere sahip olması ön test ve son testte 
öğrencilerin 25'inci maddeye ilişkin görüşlerinde anlamlı bir fark olmamasının nedeni olarak açıklanabilir.

Öğrencilerin okumaya yönelik değer algıları ölçeğin dördüncü alt boyutunda detaylı olarak incelenmiş, sonuçlar Tablo 8'de gösterilmiştir.

Tablo 8: Okuma tutum ölçeği "Değer Algısı" alt boyutu, ilişkili örnekler için t-testi sonuçları

\begin{tabular}{|c|c|c|c|c|c|}
\hline Değer AlgıSı & $\overline{\mathbf{X}}$ & Ss & $t$ & $\mathbf{N}$ & p (iki yönlü) \\
\hline $\begin{array}{l}\text { 4. Derslerde okumaya ayrılan za- } \\
\text { man çok az. }\end{array}$ & $-0,980$ & 1,014 & $-4,429$ & 21 & 0,000 \\
\hline 5. Türkçe okumak zaman kaybıdır. & $-0,280$ & 0,953 & $-1,347$ & 21 & 0,193 \\
\hline $\begin{array}{l}\text { 9, Okumayı diğer dil becerilerine } \\
\text { tercih ederim. }\end{array}$ & $-1,368$ & 0,609 & $-10,286$ & 21 & 0,000 \\
\hline $\begin{array}{l}\text { 10. Bu sinıfi bitirdikten sonra da } \\
\text { okuma dersleri almak isterim. }\end{array}$ & $-0,521$ & 0,752 & $-3,176$ & 21 & 0,005 \\
\hline 12. Okuma, hiçbir şey kazandırmaz. & 0,052 & 0,234 & 1,013 & 21 & 0,323 \\
\hline $\begin{array}{l}\text { 13. Okuma boş zamanları değerlen- } \\
\text { dirmek için iyi bir yöntemdir. }\end{array}$ & $-0,027$ & 0,775 & $-0,162$ & 21 & 0,873 \\
\hline 17. Okuma, zaman harcamaya değer. & $-0,358$ & 0,838 & $-1,956$ & 21 & 0,065 \\
\hline $\begin{array}{l}\text { 18. Ders sırasında serbest okuma için } \\
\text { daha fazla zaman olmalıdır. }\end{array}$ & $-0,671$ & 0,756 & $-4,069$ & 21 & 0,001 \\
\hline $\begin{array}{l}\text { 23. Okuma tekniklerimi geliş̧irmek } \\
\text { isterim. }\end{array}$ & $-0,107$ & 0,856 & $-0,574$ & 21 & 0,572 \\
\hline
\end{tabular}

Anadilde okuma alışkanlıklarının da etkisiyle, uygulama öncesinde ve uygulama sonrasında öğrencilerin okumaya verdikleri değer konusunda 5 'inci, 12'inci, 13'üncü ve 18 'inci maddelerde benzer görüşler belirttikleri, bu sebeple bu maddelerde anlamlı bir fark olmadığı söylenebilir. Öte yandan, öğrenciler 4'üncü ve 18 'inci maddelerde derslerde okuma için daha fazla zaman ayrılması konusunda ön test ve son testte farklı görüş bildirmişlerdir. Sesli kitap etkinliklerinin okuma kaygı düzeyini azaltması ve ders içine de dâhil edilebilirliği gibi nedenler ön test ve son test verileri arasındaki anlamlı farkın bir açıklayıcısı olarak kabul edilebilir. 9'uncu ve 10'uncu maddelerde görülebildiği gibi öğrencilerin dil becerileri arasında okumaya öncelik vermeleri ve okuma dersleri almaya devam 
etme yönündeki görüşlerinde ön test ve son test verileri arasında anlamlı farklılıklar bulunmaktadır. Öğrencilerin sesli kitapların okuma hızını artırdığı, okuma kaygısını azalttığı ve okumayı keyifli bir etkinliğe dönüştürdüğü yönündeki görüşleri aradaki anlamlı farkı açılar niteliktedir. Bununla birlikte, lisans ya da lisansüstü eğitim almak için Türkiye'de bulunan öğrenciler okuma tekniklerini geliştirme ile ilgili ön test ve son testte benzer görüşler ifade etmişlerdir. 23'üncü maddede anlamlı bir fark çıkmamasının öğrencilerin okumayı öğrenmeyle, buna bağlı olarak da akademik başarıyla ilişkilendirmelerinden kaynaklanıyor olduğu söylenebilir.

\section{Sonuç ve Öneriler}

Modern eğitim anlayışının en temel ilkelerinden biri olan, öğrenci ilgi ve gereksinimlerine uygun öğretim ortamlarının tasarlanması gerekliliği eğitimciler arasında en çok tartışlan kavramalardan biri hâline gelmiştir. Günlük yaşamımızda köklü değişimlerin öncüsü olan teknolojinin eğitimsel uygulamalarının artması, önceki nesillere göre oldukça farklı becerilere ve ilgi alanlarına sahip olan günümüz neslinin özelliklerine uygun, zenginleştirilmiş öğrenme ortamlar1nın tasarımını olanaklı kılmaktadır. Bilginin birden fazla ortamda sunulduğunda öğrenmenin daha etkili ve kalıcı olması (Mayer, 2009, s. 4), eğitimcileri birden fazla duyuya hitap eden çoklu-ortamlı öğretim malzemeleri geliştirme arayışına itmektedir.

Dört temel dil becerisinden biri olan okuma, bilgi ve iletişim teknolojilerinin yaygınlaşmasıyla birlikte göz ardı edilmeye başlanmış, günlük yaşamlarında teknolojiyi kullanma eğilimleri yüksek olan dijital nesli okumaya yönlendirmek eğitimcilerin en büyük sorunlarından biri haline gelmiştir. Günümüzde öğrenciler, serbest zamanlarının çoğunu okuma yerine dinleme ve seyretme eylemlerine ayırmaktadırlar. Öğrenci merkezli eğitimin ilkeleri hatırlandığında, bu sorunun teknoloji ile desteklemiş öğrenme ortamları ve öğretim malzemeleri tasarlanarak çözülebileceği açıktır. Bu bağlamda, işitsel ve görsel algıyı aynı anda harekete geçirerek öğrenmeyi kolaylaştıran ve öğrenilenlerin kalıcıllı̆ını artıran sesli kitaplar yabancı dil öğretiminde sıklıkla başvurulan öğretim araçları arasında yerini almaktadir. 
Bu çalışmada, sesli kitapların B1 düzeyinde yabancı dil olarak Türkçe öğrenenlerin okumaya yönelik tutumları üzerindeki etkisi araştırılmıştır. Bu amaçla, çalışmada kullanılmak üzere sesli öyküler belirlenmiş ve araştırmacı tarafından özgün olarak tasarlanan bir blog sitesi üzerinden sekiz haftalık uygulama süresince öğrencilerle paylaşılmıştır. Çalışma öncesi ve çalışma sonrasında uygulanan okuma tutum ölçeğinden elde edilen veriler ilgili araştırma sorusu bağlamında analiz edilmiştir.

Çalışmanın sonuçları, B1 düzeyinde yabancı dil olarak Türkçe öğrenen öğrencilerin sesli kitaplar kullanarak gerçekleştirdikleri okuma etkinlikleri sonucunda, okumaya karşı tutumlarının olumlu yönde değişim gösterdiğini ortaya koymaktadır. Elde edilen sonuçlara göre, uygulama sonunda öğrencilerin okumaya karşı daha istekli oldukları ve okuma kaygı düzeylerinin önemli oranda azaldığı göze çarpmaktadır. Sesli kitapların, öğrencilerin okumanın faydalarına ilişkin görüşlerini ve okumaya verdikleri değeri de olumu yönde etkilediği çalışmanın sonuçları arasındadır.

Teknolojinin çekiciliği karşısında okumaya duyulan ilginin giderek azald1ğı günümüzde, öğretim teknolojileri ile desteklenen okuma öğretimi dijital neslin okumaya karşı ilgilerini artıran bir etken olarak karşımıza çıkmaktadır. Bu açıdan bakıldığında, çalışma çoklu-ortamlı öğrenme kuramını destekleyici nitelikte bulgular içermektedir. Teknolojiden faydalanılarak birden fazla duyunun öğrenme sürecine dâhil edilmesi, yabancı dil olarak Türkçe öğretiminde okumaya karş1 tutumu, buna bağlı olarak da motivasyonu ve okuma başarısını olumlu yönde etkileyecektir.

Sesli kitapların B1 düzeyinde yabancı dil olarak Türkçe öğrenen üniversite öğrencilerinin okumaya yönelik tutumları üzerindeki etkisinin araştırıldığı bu çalışma, kapsamı ve sınırlı1ıkları açısından bu alanda daha fazla çalışmaya gereksinim olduğunu göstermektedir. Benzer bir yöntemle farklı yeterlik düzeylerinden katılımcılarla yürütülecek ileriki bir çalışmayla, sesli kitapların düzeyler bağlamında etkisi karşılaştırılabilir. Öğretimin diğer kademelerini de kapsayacak şekilde daha geniş ölçekli bir çalışma yürütülerek farklı yaş gruplarından öğrencilere uygun öğretim malzemeleri geliştirilebilir. İleride yürütülecek benzer yöntemli bir çalışma ile sesli kitapların dinleme becerisine etkisi de araştırılabilir. 
Geleneksel yöntemlerin, teknoloji ile bütünleşik yaşamlar süren günümüz neslinin ilgi ve gereksinimlerini karşılamada yetersiz kaldığı açıkça görülmektedir. Çalışmada ulaşılan sonuçlar, günlük yaşamda kullanılan basit teknolojilerin eğitimsel amaçlarla kullanıldığında öğrenmeye karşı ilgiyi artıran önemli bir unsur olduğunu göstermektedir. Bu bağlamda, öğrenci ilgi ve gereksinimlerine uygun teknoloji aracılı öğrenme ortamları tasarlamak eğitimciler, materyal geliştirenler ve program tasarımcıların ortak çalışma alanı olmalıdır. 


\section{Kaynaklar}

Ajzen, I. (2005). Attitudes, Personality, and Behaviour (2 ed.). Maidenhead: Open University Press.

Almasi, J. F. (2003). Teaching Strategic Processes in Reading. New York: Guilford Press.

Avrupa Konseyi. (2013). Diller için Avrupa Ortak Öneriler Çerçevesi Öğrenim, Öğretim ve Değerlendirme (2 ed.). Almanya: telc $\mathrm{GmbH}$.

Bohner, G., \& Weanke, M. (2002). Attitudes and Attitude Change. New York: Psychology Press.

Bursuck, W. D., \& Damer, M. (2007). Reading Instruction for Students Who are at Risk or Have Disabilities. Boston: Pearson/Allyn and Bacon.

Carnine, D. W., Silbert, J., Kame'enui, J. E., Tarver, S. G., \& Jungjohann, K. (2006). Teaching Struggling and At-Risk Readers: A Direct Instruction Approach (3 ed.). Upper Saddle River, New Jersey: Pearson Merrill Prentice Hall.

Carrell, P. L., Devine, J., \& Eskey, D. E. (1988). Interactive approaches to second language reading: Cambridge University Press.

Demirtaş-Madran, H. A. (2012). Tutum, Tutum Değişimi ve İkna (1 ed.). Ankara: Nobel.

Esteves, K. J., \& Whitten, E. (2011). Assisted reading with digital audiobooks for students with reading disabilities. Reading Horizons, 51(1), 21.

Friedland, A., Gilman, M., Johnson, M., \& Demeke, A. (2017). Does Reading-While-Listening Enhance Students' Reading Fluency? Preliminary Results from School Experiments in Rural Uganda. Journal of Education and Practice, 8(7), 82-95.

Grabe, W., \& Stoller, F. L. (2001). Reading for academic purposes: Guidelines for the ESL/ EFL teacher. In M. Celce-Murcia (Ed.), Teaching English as a second or foreign language (3rd ed., pp. 187-203). Boston, MA: Heinle \& Heinle.

Grabe, W., \& Stoller, F. L. (2002). Teaching and researching reading. London: Pearson.

Gunning, T. G. (2014). Assessing and Correcting Reading and Writing Difficulties (5 ed.).

Boston: Pearson.

Guthrie, J. T., \& Wigfield, A. (2005). Roles of Motivation and Engagement in Reading Comprehension Assessment. In S. G. Paris \& S. A. Stahl (Eds.), Children's Reading Comprehension and Assessment (pp. 187-213). Mahwah, New Jersey: L. Erlbaum Associates.

İnce, B., \& Güleç, İ. (2018). Türkçe Öğrenen Yabancılar için Türk Edebiyatı Antolojisi. İstanbul: Medeniyet Üniversitesi Yayınları.

İnceoğlu, M. (2011). Tutum algı iletişim (6 ed.). Ankara: Siyasal Kitabevi. 
Jennings, J. H., Caldwell, J. S., \& Lerner, J. W. (2006). Reading Problems: Assessment and Teaching Strategies. Boston, USA: Pearson Education.

Johnson, A. P. (2016). 10 Essential Instructional Elements for Students With Reading Difficulties: A Brain-Friendly Approach. California Corwin.

K. Klingner, J., Vaughn, S., \& Boardman, A. (2007). Teaching Reading Comprehension to Students with Learning Difficulties New York: Guilford Press.

Kayalan, M. (1992). Etkili ve Hızlı Okuma Sanatı (1 ed.). İstanbul Real Yayıncılık.

Kilpatrick, D. A. (2015). Essentials of Assessing, Preventing, and Overcoming Reading Difficulties. Hoboken Wiley.

Lipson, M. Y., \& Wixson, K. K. (2013). Assessment and Instruction of Reading and Writing Difficulty: An Interactive Approach (5 ed.). New Jersey: Pearson.

Mayer, R. E. (2009). Multimedia Learning (2 ed.). Cambridge: Cambridge University Press.

Rashtchi, M., \& Hajihassani, H. (2010). Blog-assisted Language Learning: A Possibility in Teaching Reading to Iranian EFL Learners. International Journal of Language Studies (IJLS), 4(4), 245-262.

Rasinski, T. V., Padak, N. D., \& Fawcett, G. (2010). Teaching Children Who Find Reading Difficult (4 ed.). Boston, MA: Allyn \& Bacon.

Rubin, D., \& Opitz, M. F. (2007). Diagnosis and improvement in reading instruction. Boston Pearson/Allyn \& Bacon.

Sesli Edebiyat: Öyküler Sesleniyor 1. (2007). (G. Göksel Ed.). İstanbul: Deniz Kültür Yayınları.

Sesli Edebiyat: Öyküler Sesleniyor 2. (2009). (G. Göksel Ed.). İstanbul: Deniz Kültür Yayınları.

Smith, M. C. (1990). A longitudinal investigation of reading attitude development from childhood to adulthood. The Journal of Educational Research, 83(4), 215-219.

Taguchi, E., Takayasu-Maass, M., \& Gorsuch, G. J. (2004). Developing reading fluency in EFL: How assisted repeated reading and extensive reading affect fluency development. Reading in a Foreign Language, 16(2), 70-96.

Türker, S. (2010). Sesli Kitapların Yabancı Dil Olarak Ingilizce Öğrenen Farklı Yeterlik Seviyesindeki Üniversite Öğrencilerinin Okudukları Metinleri Anlamalarına Olan Etkisi. (Yüksek Lisans Tezi), İhsan Doğramacı Bilkent Üniversitesi, Ankara, Türkiye.

Wagar, C. R. (2016). The Impact of Audiobooks on Reading Comprehension and Enjoyment. Western Governors University, Salt Lake City, UT.

Wallace, C. (1996). Reading. In H. G. W. C N Candlin (Ed.), Language Teaching: A Scheme for Teacher Education (pp. 21-27). Oxford: Oxford University Press. 